\title{
Complex Creative Systems
}

\author{
Principles, processes, and practices of transformation \\ By Fred Provenza, Hugh Pringle, Dean Revell, Nan Bray, Chip Hines, \\ Richard Teague, Tim Steffens, and Matt Barnes
}

\section{On the Ground}

- Landscapes are complex creative systems that are endlessly emerging, transforming, and vanishing as a result of ever-changing relationships among organisms and environments-soil, plants, herbivores, and human beings. In the process, all organisms are actively participating in creating environments; they aren't merely adapting to them.

- Researchers and managers attempt to understand and manage creative relationships among soil, plants, herbivores, and human beings, but we have become increasingly separated from one another in our endeavors. When we work in partnerships, we can better learn about biophysical processes and participate in managing as landscapes continually create.

- To do so, researchers must combine their reductionist thinking and intent to develop "best management practices" with new approaches that consider creative systems. In turn, managers must come to appreciate the value of "reductionist" research for understanding processes and developing principles that apply generally across time and space.

- The challenges we face in addressing "critical issues" have little to do with the issues and much to do with crossing the divides that polarize and isolate us. The irony is that working together to transcend the boundaries we create is addressing the "really big issue."

Keywords: complexity, creativity, organisms, relationships, interdependence, human beings.

Rangelands 35(5):6-13

doi: 10.2111/RANGELANDS-D-13-00013.1

(C) 2013 The Society for Range Management

rganisms and landscapes are ever in the process of creating relationships in which all things incessantly arise, transform, and vanish. In such environments, organisms don't survive by merely adapting to where they live. Instead, they actively participate in creating conditions to thrive. Creative engagement means nurturing ever-changing relationships as landscapes transform. By engaging in ways that cultivate and affirm creativity, we can influence change, though our actions inevitably cause some outcomes no one anticipates. Our ability to create as systems ever transform is enhanced when scientists and managers rekindle our relationships with one another and with the landscapes we inhabit.

\section{Principles of Creativity}

All organisms, from those in soil to plants and animals to human beings, are continually evolving as environments change. They are involved in games of offense and defense; biological and chemical warfare; production, consumption, and creation. If we can become better aware of our own ongoing evolution, we will sense and perhaps even embrace a world in which we and all living things are changing at every 
instant. The notion that the world around us changes constantly, mostly a platitude repeated thoughtlessly, will become authentic.

\section{Genes, Organisms, Environments}

According to Darwinian theory, species evolve when genetic mutations valuable for survival are passed on to the next generation. This notion has come to connote rather rigid and passive ways of evolving as environments change inexorably during the lifetime of individuals. ${ }^{1}$

Ever-changing conditions require that genes continually interact with environments. This process is enabled by plasticity in gene expression-including epigenetic changes in phenotypes that can persist over generations-which creates other ways of generating new biological forms, functions, and behaviors. ${ }^{1}$ This dialogue, which begins in utero and early in postnatal life, prepares an organism for the environment where it will live. Chance also plays a role-what Lewontin refers to as "noisy development" that occurs at the molecular level during development in utero and early in life. ${ }^{1}$ Relationships among genes, organisms, ever-changing environments, and chance ensure no two individuals are alike in form (how they are built morphologically), function (how they work physiologically), or behavior (what they do).

From conception to the grave, the needs of individuals change, as do the environments where they live. Throughout life, individuals create relationships among what they deem are relevant facets of biophysical environments. Importantly, organisms don't merely respond (adapt) to the environments where they live, they actively participate in constructing (creating) them. ${ }^{1}$ These dynamics suggest that we should take our views of evolution beyond an account of how organisms developed from earlier forms during the natural history of the species to include changes occurring within the lifetime of the individual. This view would recognize that individuals are involved in the world, which enables them to evolve in the world.

Life is ever creating its way into the future by engaging in new cooperative relationships. Ironically, as organisms evolve in the world, they alter the environments they inhabit in ways that make life less hospitable for them and more hospitable for others. To postpone demise, all creatures must periodically change direction, but they generally don't do that. Rather, they typically end up running ever faster in the same direction, which only makes matters worse. Eventually, organisms, ${ }^{1}$ organizations, ${ }^{2}$ and spe$\operatorname{cies}^{3}$ run out of creative energy - they are no longer able to cope with the changes in the environments they helped to create.

This highlights the value of embracing the interdependent and ever-changing nature of entire systems, rather than fixating on conserving a particular facet of a system. When we attempt to favor some organisms and organizations over others, as we often do in agriculture and conservation, we can inadvertently contribute to their demise by depleting the inputs they require. We often deal with the simplified systems we create by adding expensive inputs, which can't be sustained in perpetuity, rather than by creating webs of interdependencies where food (e.g., plants) for one organism ultimately nourishes (e.g., urine, feces, and carcasses) the next. By considering multiple components of systems, we are more likely to create situations where energy and nutrients are cycled in ways that each organism and organization is replenished by the end-products of another. Nurturing interdependencies can confer system resilience and buffer against catastrophic changes so widely documented for modern land use. ${ }^{4}$

\section{Principles of Landscape Behavior}

Geomorphology, soil, and hydrology affect resource availability — water, nutrients, and sunlight—which affects the kinds and chemical characteristics of plants species that grow in an area. ${ }^{5}$ Over long periods, resource-rich environs promote survival of species with high levels of primary compounds and low levels of secondary compounds, characteristics that encourage use of plants and habitats by herbivores. Conversely, resource-poor environments deter herbivores by favoring species with high levels of secondary compounds. On a daily basis, resource availability affects how plants allocate resources to grow or defend. ${ }^{5}$ High resource availability favors growth over defense, particularly with carbon-based compounds such as phenolics and terpenes. Conversely, low resource availability retards growth and increases defense.

The relationship between organisms and landscapes is reciprocal-they transform each other perpetually. ${ }^{6,7}$ For instance, people influence resource availability-water and mineral availability-by how we manage grazing. Animal impacts can increase or decrease resources for plants by affecting 
soil organic matter and temperature, water infiltration, and plant species diversity. Plant diversity and chemistry influence the chemical characteristics of herbivore diets, which in turn affect the chemical characteristics of plants and animals people eat. ${ }^{8}$

Successful managers don't focus on one (biological) without the other (physical), though many scientists have attempted to do so for the past two centuries, despite more holistic approaches of ecologists such as Cowles and Clements. Much of classical rangeland ecology (Sampson, Renner, and Dyksterhuis) was based on simplifications of Cowles and Clements, who emphasized feedbacks between organisms and physical environments. We can't understand ecosystems without this holistic perspective. With this view, creative opportunities are vast. Without it, we are confined to simplistic "biocentric" views of landscapes.

\section{Processes of Creativity}

A process is a series of actions that change form, function, and behavior. Scientists often study processes as if they were events: What foods do animals eat (diet selection)? Where do they go (habitat selection)? Our views of diet and habitat selection transform from events into dynamic processes when we ask how and why organisms behave as they do and when we link processes at all scales to understand emergent behaviors. When we attempt to study or manage processes as if they were events we fail to appreciate that climate, soil, plants, herbivores, and human beings are not static. They constantly transform in mutual interdependence.

In grazing management, creative processes involve interactions among climate, soil, plants, herbivores, and humans. Historically, plants and animals moved about landscapes as climate and weather regimes changed. ${ }^{3}$ With livestock, these relationships emerge from constraints and incentives imposed by different management schemes, which affect: 1) Plant Behavior-allocation of resources to grow or defend as affected by stocking rate relative to grazing capacity and recovery time between defoliations; 2) Animal Behavior - intensity, frequency, time, and location of grazing exhibited by different species of herbivores, as well as individuals within species that exhibit dissimilar preferences for forages and habitats; and 3) Distribution of Resources - the mix of landscape features and how herbivores learn to use them including plant communities, water, mineral resources, and topography that affect the distribution of animals across a landscape through successions that include daily, weekly, and seasonal changes.

Below ground, life in soil nourishes plants which nourish life in the soil. ${ }^{9}$ Above ground, plants protect soil from wind and water and nourish animals, which in turn nourish soil and plants. Removal of too much plant tissue, and the ensuing lack of residual biomass by grazing that's too frequent or intense, reduces the potential to dissipate the energy of raindrops and overland flow and removes protection from solar energy which can raise soil temperature to levels that thwart soil organisms from performing functions vital for plants and animals. The erosive energy of wind and water and the decrease in organic matter additions to soil adversely affect bulk density, biotic crusts, aggregate stability, and organic matter content, diminishing infiltration and increasing erosion and runoff. Collectively and most importantly, these factors affect the kinds and chemical characteristics of plants that can grow in an area.

Soil, plants, and animals benefit when herbivores roam. These behaviors they do naturally, when unconfined, in response to changes in forage quality and availability and to predators. Beyond that, satiety mechanisms ensure herbivores eat a variety of foods and forage in a variety of places. ${ }^{10,11}$ Variety stimulates appetite and enhances nutrition, production, and health. Eating combinations of foods that meet needs is satisfying. Conversely, if a diet is lacking in phytochemical diversity, such that animals are never satisfied, the ensuing malaise causes animals to form aversions to diets they are eating and to seek other foods and places to forage.

Herbivores experience consequences (satiety) that encourage movement as a result of using resources (forages) and excreting waste products (feces and urine). By promoting movement, satiety reduces overgrazing and can create diverse plant species with different chemical characteristics, enhance soil organic matter and nutrients, moderate soil temperature, and increase water infiltration rates. Movement also reduces parasites and diseases in herbivores.

We often limit the ability of herbivores to move, either by physical constraints such as fences-including designated boundaries for nature conservation areas - or positions of supplements and water. We also unknowingly impose behavioral constraints whereby animals aren't allowed to learn from their mothers or peers the benefits of moving or given the chance to figure it out for themselves. We often 
don't build regular movement and exploration into their cultures, so animals become neophobic - we train them to be wary of new foods and places, though we can also train them to use new foods and habitats. ${ }^{12}$

We further restrict selection by planting monocultures of forages or fencing in ways that reduce plant diversity, unaware of the impacts on animal behavior. We have not fully appreciated that the mix of plants on offer, and their biochemical complementarities, has a major impact on how animals learn to select diets and habitats. ${ }^{8,10,12,13}$ Richard Fyn and his colleagues have emphasised the decline of numerous sub-Saharan migratory herds, despite an increase in protected areas, because migratory routes have been blocked by land use changes that separate wet and dry season grazing resources. Property boundaries and fixed water points are conventions of society that for the time being are parts of livestock management. Land managers must learn as much as possible about these relationships to try to provide the diversity of vegetation and movement of animals on spatial and temporal scales that benefit both plants and animals. Similar to the many case studies highlighted in this issue of Rangelands, pastoralists in Namibia, Botswana, and South Africa are now fencing pastures to include as much diversity as possible, as opposed to fencing for homogeneity, due to better performance of livestock given choices (Riaan Dames, personal communication, 2011).

\section{Practices of Creativity}

\section{In Science}

In science, creativity is manifest as a quest to understand processes of change. Fundamental processes in physics are relationships among energy and matter. Their inflections are elementary particles that make up atoms that create the galaxies, the stars, the planets, and life. Fundamental processes in biology are genes expressed through interactions with ever-changing social and biophysical environments. Local manifestations are myriad species and the forms, functions, and behaviors of individuals and cultures. The functioning of processes transcend time and space, but their manifold inflections are unique in time and space. Processes are easily confused with their manifestations, all uniquely emerging in space and time as landscapes transform within particular ecological, social, and economic contexts. ${ }^{13,14}$

To understand the behavior of organisms and environments, we attempt to develop principles about processes. Principles help guide our expectations of possible outcomes, but they don't guarantee certainty about the outcomes. An unexpected outcome doesn't necessarily mean the principles are wrong, but rather reflects the dynamism of biophysical processes and our incomplete knowledge. Through such experiences, we learn about the behavior of organisms and landscapes that we didn't previously understand. In the end, all concepts and theories are limited and approximate. Science cannot be perceived as "true" or "final" in any absolute sense. It is a tentative organization of working hypotheses that best account for biophysical processes whose interconnections are the fabric of a web characterized by change. ${ }^{14}$

In principle, scientists are "objective" observers, but in reality, there are no "unbiased observers." Quantum physicists accept this property of nature, as have scientists in many other disciplines. To what degree do we cling to the "objective observer" notion, unaware that by participating, in science or in practice, we are creating the realities we observe? When researchers conduct trials to compare various "grazing systems," they move from developing principles about processes to implementing practices distinct in space and time. They become managers of case studies: the questions they ask, the ways they design and implement their studies, and the ways they measure responses and interpret findings all influence outcomes.

In any study, researchers can control variables or work in a realistic context, but not both. To the degree that researchers can control variables they can ascribe cause to a particular treatment, but only within the context of their study. Conversely, to the degree researchers have realistic context they lose the ability to control variables and they are unable to ascribe cause to any one factor. Case studies of people who manage landscapes (e.g., grazing studies) or of populations (e.g., epidemiological studies) describe events in the "real world" but they, too, are limited to the context of the study. Life is not without cause, but it is so multicausal that attempts to control all the variables are impossible to implement and problematic to interpret.

In "reality," we aren't good at predicting or controlling change. We interact with biophysical environments and adjust our behavior based on whatever feedback we can gain, a process that in both science and practice involves setting goals, anticipating as best we can future dynamic conditions, devising 
flexible strategies that embrace change, monitoring, and continually re-creating. ${ }^{2,15}$ The key point with regard to creativity is this: If, as quantum physicists argue, chance is playing a role in the unfolding of the universe, ${ }^{16}$ and if "noisy development" is playing a role in creating individuals, ${ }^{1}$ then existence is literally ever creating its way into the future. No two moments in time or conditions in space are alike, each uniquely in the process of coming into being-becoming.

The point isn't to conclude that it's all too hard and to give up in despair. Rather, we should endeavor to rise to the challenge of continually enquiring and observing within the constraints of our circumstancesexperimental designs, funding, and time - and to continuously consider discrete parcels of knowledge within a broader and ever-changing context. In the process, we can extract principles about processes to help guide our expectations and actions. Some people can straddle these two worlds of reductionism and holism, but for most people, forming teams and sharing knowledge creates the best learning outcomes.

\section{In Management}

In practice, creativity is manifest when a land manager "paints on the canvas" we call a landscape. Managers paint using understanding of relationships among different "colors"- soil, plants, and animals. The challenge of adequately embracing multiple causes and outcomes over time and space translates into transforming with the landscapes we inhabit. This year will not be like last year-ecologically (rain), economically (commodity prices, interest rates), or socially (consumer preferences, regulatory environment) - so don't manage this year like last year. Like a sailor returning to a race won last year, there are some "givens" - that big rock is still there, avoid it. But the winds change and the swell will be different. By sailing the same way this year as last, he or she might avoid the rock, but lose the race. Sailors are smarter than that. They are cunning in their dexterity to manipulate changing conditions to their ends.

Managers can best evolve-manipulate changing conditions to their ends-within prevailing ecological, economic, and social conditions by linking understanding of principles and processes with the flexibility to respond to ever-changing environments. Working with practitioners, researchers can provide understanding of principles and processes and link them with the two critical decision-making processes of land managers: preemptive and creative management within the framework of their uniquely personal holistic contexts.

The process of creating in science and practice is enabled through dialog-the free flow of ideas among peoples of diverse backgrounds. Suspending assumptions and speaking from the heart liberates scientists and managers from the narrow prisms and boundaries of predominant beliefs, the "prevailing theories" and "best management practices" of the day. Beliefs in science and practice, meant to inform and guide us, all too often fashion borders that confine us. All beliefs are limited and approximate - we create them and then, without warning, we find ourselves confined within them. Attempting to understand, with the goal of predicting and controlling the future, are conventional paradigms. They are illusions once we embrace dynamism, uncertainty, and creativity. That's the challenge for scientists and managers alike.

The business world is littered with carcasses of organizations that tried to run ever faster in the same direction. Their success blinded them to ongoing change. On the other hand, some companies thrive because they transform. To do so, Senge argues in The Fifth Discipline-The Art and Practice of the Learning Organization, ${ }^{2}$ they encourage: 1 ) ongoing growth of individuals (personal mastery); 2) developing awareness of changes arising socially, economically, and ecologically (surfacing and questioning mental models); 3) integrating knowledge of everyone in the group (team learning); 4) enabling people to develop shared goals (building shared vision); and 5) embracing the interdependent and dynamic nature of reality (systems thinking).

\section{In Science and Management}

Managers like Nan Bray, Chip Hines, and Matt Barnes describe what they do in terms that reflect Senge's learning organisations. In the realm of personal mastery, they work to keep their minds open to alternative explanations and ways of acting, recognizing that complex creative systems do that effortlessly, all the time. As part of increasing awareness of their context, they try to observe this "whole" as objectively as possible, paying attention to details, being willing to speculate about the meanings behind observations, and acting on the basis of deductions and intuitions. Team learning in this context means learning from soil, plants, and animals as well as other humans, and integrating that learning leads to an ability to act decisively when necessary. Even if the decision is "wrong," by observing carefully it is possible to realise October 201311 the "mistake," learn from it, and change yet again. Most important- 
ly, perhaps, these managers recognize that they are not really "managing" but rather "guiding" a complex, everchanging system. Over time, they've learned to look for, and enjoy, dynamic changes in the system. They don't expect their systems to "settle down" and be managed the same way year after year-in striking contrast to the use of the phrase "grazing system" in traditional grazing management.

Hugh Pringle and Ken Tinley experienced the five disciplines essential for managers and scientists to succeed through Ecosystem Management Understanding $\left(\mathrm{EMU}^{\mathrm{i}}\right)$. Together with pastoralists they built a working model of the Murchison River Catchment in Western Australia that described what had gone wrong and what was needed

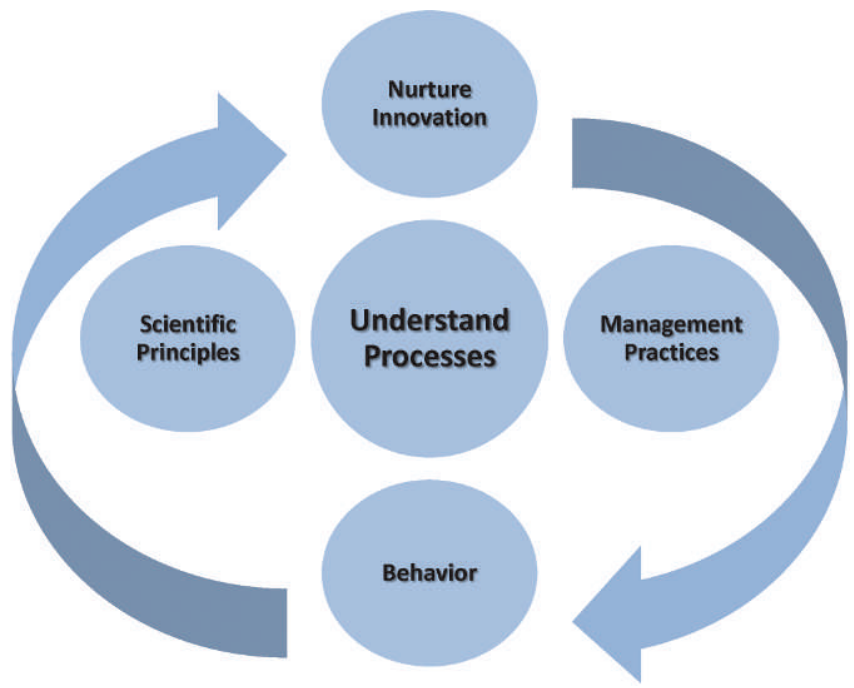

Figure 1. BEHAVE integrates scientific principles about processes with local knowledge to enhance ecological, economic, and social values of rural and urban communities.

to heal the system. Pastoralists first recorded their knowledge on transparent overlays of maps of their properties. They next flew over their properties to get a "bird's-eye view." Everybody then mapped and shared observations and knowledge. Finally, they visited areas that needed work. Pastoralists began viewing their properties in a new-holistic-light. "I have changed the way I see the land so much that I don't really remember how I used to see it" (Burke, personal communication, 2003). The icing on the cake was when pastoralists said they wanted to work together because salient features transcended property boundaries. This process was not "extension" or "technology transfer" - it was building mutual trust, respect, and learning. ${ }^{7}$

The desire to integrate principles, processes, and practices led in 2001 to the formation of an international network of scientists and land managers from five continents. That consortium, which is known as Behavioral Education for Human, Animal, Vegetation, and Ecosystem Management (BEHAVE Fig. 1), integrates principles and processes with local knowledge to enhance ecological, economic, and social values of rural and urban communities. Our goal is to assimilate understanding of behavioral principles and processes with local knowledge to facilitate transitions as soil, plants, herbivores, and human beings evolve with social, economic, and ecological changes. A deep appreciation of the importance of embracing change transforms peoples' philosophies and practices from rigid and unyielding to fluid and malleable. We no longer view creatures, including ourselves, as machines and genes as destiny. Rather, we grasp how to use behavioral interrelationships to create an array of opportunities with which to meet the challenges people face as they embrace constant change. In BEHAVE, we are all students continually attempting to understand processes, develop principles, and implement practices.

Working with farmers and ranchers in programs like EMU and BEHAVE is an extremely liberating and rewarding change from tradition. Learning how managers cope with challenges inspires scientists to think creatively about research. In turn, learning about behavioral principles and processes inspires managers to fashion innovative practices. In the process, we rekindle our relationships with one another and the landscapes we inhabit.

Creative engagement requires effort nurturing relationships with one another and with the landscape communities we inhabit. As with any relationship, that takes time and it is dynamic. In the process, researchers learn to shed their longing for reductionist control and a tradition of "teaching" managers about "best management practices" and instead develop creative, mutually supporting learning partnerships. In turn, managers come to appreciate the value of "reductionist" research for understanding processes and developing principles.

For more information on the Ecosystem Management Understanding (EMU) project, see emuproject.org.au.

ii For more information on the Behavioral Education for Human, Animal, Vegetation, and Ecosystem Management (BEHAVE) project, see behave.net. 
By engaging in ways that cultivate and affirm creativity, we can influence change, though our actions inevitably cause some outcomes no one anticipates- because we don't know enough to foresee, because the world responds to our actions in ways no one expects, or because we are unable to evolve with the changes we help create. In attempting to study or manage landscapes, we typically long for control, despite being awash in variability and uncertainty largely outside our ability to predict or control. The challenge we face is to avoid illusions of stability, control, and permanence and to embrace inexorable cycles of transformation. We resist such change by declaring wars-for example on invasive species, various diseases including cancer, and climate change - and fighting battles against anything that threatens constancy under the guise of "saving the world." To do so, we focus myopically on an enemy, ignoring the interdependent and ever-changing nature of existence.

The point, simply, is this: The challenges we face in addressing any "critical issue" of the day have little to do with the issue and much to do with crossing the divides that polarize and isolate us. The strange and wonderful irony is that working together with open hearts and minds to transcend the boundaries we create is addressing the "really big issue."

\section{References}

1. Lewontin, R. 2000. The triple helix: gene, organism, environment. Cambridge, MA, USA: Harvard University Press. 136 p.

2. Senge, P. M. 1994. The fifth discipline: the art and practice of the learning organization. New York, NY, USA: Currency Doubleday. $423 \mathrm{p}$.

3. Pielou, E. C. 1991. After the ice age: the return of life to glaciated North America. Chicago, IL, USA: University of Chicago Press. 366 p.

4. Gunderson, L. H., And C.S. Holling [eds.]. 2002. Panarchy: understanding transformations in human and natural systems. Washington, DC, USA: Island Press. 507 p.

5. Herms, D. A., and W. J. Mattson. 1992. The dilemma of plants: to grow or defend. Quarterly Review of Biology 67:283-335.

6. TINLEY, K. L. 1987. Achieving a balance between long and short term research in nature conservation. In: D. A. Saunders, G. W. Arnold, A. A. Burbidge, and A. J. M. Hopkins [EDs.]. The role of remnants of native vegetation. Chipping Norton, NSW, Australia: Surrey Beatty and Sons Pty Ltd. p. 347-350.

7. Pringle, H., and K. L. Tinley. 2003. Are we overlooking critical geomorphic determinants of landscape change in Australian rangelands? Ecological Management and Restoration 4:180-186.

8. Provenza, F. D. 2008. What does it mean to be locally adapted and who cares anyway? Journal of Animal Science 86:E271-E284.

9. BASKIN, Y. 2005. Under ground: how creatures of mud and dirt shape our world. Washington, DC, USA: Island Press. 237 p.

10. Provenza, F. D. 1996. Acquired aversions as the basis for varied diets of ruminants foraging on rangelands. Journal of Animal Science 74:2010-2020.

11. Bailey, D. W., and F. D. Provenza. 2008. Mechanisms determining large-herbivore distribution. In: H. T. T. Prins and F. van Langevelde [EDs.]. Resource ecology, spatial and temporal dynamics of foraging. Dordrecht, the Netherlands: Springer. p. 7-28.

12. Meuret, M., and F. Provenza [eds.]. 2013. Shepherds' know-how. Austin, TX: ACRES U.S.A. In press.

13. Teague, R., F. Provenza, U. Kreuter, T. Steffens, and M. Barnes. 2013. Multi-paddock grazing on rangelands: why the perceptual dichotomy between research results and rancher experience. Journal of Environmental Management 128:699-717.

14. Provenza, F. D. 2000. Science, myth, and the management of natural resources. Rangelands 22(4):33-36.

15. Savory, A., And J. Butterfield. 1999. Holistic management: a new framework for decision-making. Washington, DC, USA: Island Press. $623 \mathrm{p}$.

16. Lindley, D. 2007. Uncertainty: Einstein, Heisenberg, Bohr, and the struggle for the soul of science. New York, NY, USA: Anchor Books. 257 p.

Authors are Professor Emeritus, Dept of Wildland Resources, Utah State University, Logan, UT 84322, USA, fred.provenza@usu.edu (Provenza); Private Consultant, Ecosystem Management Understanding (EMU), Edith Cowan University, Alice Springs, NT 0871, Australia (Pringle); Principal Scientist, CSIRO Sustainable Agriculture Flagship, Wembley, Western Australia 6913; School Animal Biology, University of West- 
ern Australia, Nedlands, WA 6009, Australia; CSIRO Livestock Industries, Wembley, WA 6913, Australia; Future Farm Industries Cooperative Research Centre, University of Western Australia, Crawley, WA 6009, Australia (Revell); Farmer, Dragon Point Enterprises, Oatlands, TAS, 7120, Australia (Bray); Rancher and Consultant, 615 South Ivy, Yuma, CO 80759, USA (Hines); Professor, Ecosystem Science and Management, Texas A E'M University, College Station, TX 77843, USA, and Texas A ${ }^{\prime} M$ AgriLife Research, Texas A ${ }^{\prime} M$ University System, Vernon, TX 76384, USA (Teague); Assistant Professor, Dept of Agricultural Sciences, West Texas AEM University, Canyon, TX 79016, USA (Steffens); and Owner and Rangeland Consultant, Shining Horizons Land Management, LLC, and Field Director for Rangeland Stewardship, Keystone Conservation, Bozeman, MT 59771, USA (Barnes). This is published with the approval of the Director, Utah Agricultural Experiment Station, and Utah State University, as journal paper number 8537. 